\title{
DRAGONOLOGY: THE IDEA OF THE DRAGON AMONG THE GREEKS AND THE ZULU
}

\author{
M Kirby-Hirst (UNISA)
}

\begin{abstract}
The dragon is one of the most ubiquitous of images - from its appearance in the dreams of individuals to the legendary works of men like J R R Tolkien - it is known across the world but never viewed in the same way. This article takes a Jungian psychoanalytic approach to the dragon as symbol, and juxtaposes two distinct perspectives on the dragon, that of the ancient Greeks (the mythic dragons Typhon and Python in particular) and the Zulu people of South Africa (with special attention given to the place of the python as a possible "dragon" in the practice of divination), in an effort to better understand the creature's significance to these two cultures and to the world at large.
\end{abstract}

Then a second sign appeared in the sky: there was a huge red dragon with seven heads and ten horns, and each of the seven heads crowned with a coronet. Its tail swept a third of the stars from the sky and hurled them to the ground ... (Rev. 12:3-4).

In the western world the dragon most often occurs as the perfect expression of malefic and destructive capacity - the dragon of St. John's vision or the feared Leviathan of Hebrew myth - while in the east dragons can be representative of good fortune. Yet wherever one is in the world, almost every society, past and present, often expresses some concept of the dragon: images of dagger-toothed reptilian beasts abound, with great bat-like wings, poisonous spines, sharp claws, and fiery breath the optional extras filled in by the individual imagination. The surface-dwelling dragons of ancient India for example, were believed to be responsible for the creation of magical gems that the canny individual might steal for his own purposes (Philostr. VA 3.6-8). Where then do these beliefs spring from? Comparative analysis provides a means of addressing this question, and therefore, I have centred this investigation on ancient Greek manifestations of draconic lore, with local Zulu legend as my comparandum, chosen specifically to reveal the global application of these beliefs, be they Afro- or Eurocentric. ${ }^{1}$ This will occur on

The comparative method is employed in this discussion as a means of assessing the similarities and differences that are apparent in Greek and Zulu conceptions of dragons. Ragin 1994:105 refers to this action of comparison as investigating "diversity", and this is something that Lambert (e.g. 1990, 1993, 1995) in particular has engaged in with great success. This manner of research reveals that there is something to be gained from the juxtaposition of two such obviously different and yet, startlingly similar societies as 
an essentially psychoanalytic platform, with which some form of generalised "meaning" might be attributed to this commonly occurring creature and its place in the human imagination.

In ancient Greek the word "dragon" has two basic possible derivations -

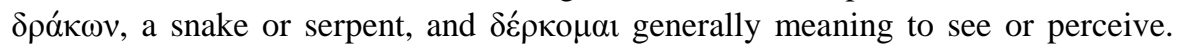
Huxley (1979:6) links this notion of observation with the avaricious nature of dragons in western thought, with an example being J R R Tolkien's great dragon, "Smaug" in The Hobbit. Originally then, the dragon could be any sort of snake, an inaccuracy that perhaps explains the vast differences in sizes, shapes, and abilities of these monstrous creatures as they appear in myths, legends, and fables. ${ }^{2}$ Carl Sagan is quoted as saying that dragons are an echo in the human mind of a time when we struggled against the apparently overwhelming natural world (Newman 1979:255). The dragon is thus a dual symbol, capable of expressing either good or evil, characterizing the relationship between nature and humankind's civilized world, embodying both the urge to create and to destroy, the Freudian Eros and Thanatos. Freud, never makes use of the term Thanatos, ${ }^{3}$ referring instead to a "death-instinct" (Freud 1947:55), but it is from this perspective that Eros — the "self-preservative instinct" — is countered by the death-instinct which ultimately seeks to "lead organic matter back into the inorganic state" (Freud 1947:55). The position of dragons on this continuum of belief, placed somewhere between destruction and creation, depends largely on the

the ancient Greeks and the Zulu people of KwaZulu-Natal. The psychological perspective that I have added to this analysis suggests that something greater can be gleaned regarding the essential truth of the human spirit that Jung was intrigued by when he first posited ideas like the collective unconscious. Indeed, as Dodds 1951:102 comments, "man shares with a few others of the higher mammals the curious privilege of citizenship in two worlds", the physical and spiritual worlds.

2 David Gilmore 2003:1 comments that " ... the mind needs monsters. Monsters embody all that is dangerous and horrible in the human imagination". The dragon as a concept possibly derives from the archaic notion of the "scapegoat" and is thus a religious, psychological, and social complex aimed at catharsis and expiation. The word "monster" itself, stemming from the Latin monere, "to warn", also hints at this fact, and is suggestive not only of human fear and guilt, but of violence and aggression as well. It is indeed the case that the creation and slaying of monsters like dragons is psychic catharsis in the extreme. Thus it is that Gilmore 2003:194 concludes: "The power of monsters is their ability to fuse opposites, to merge contraries, to subvert rules, to overthrow cognitive barriers, moral distinctions, and ontological categories. Monsters overcome the barrier of time itself. Uniting past and present, demonic and divine, guilt and conscience, predator and prey, parent and child, self and alien, our monsters are our innermost selves".

3 In the popular imagination it is however the terms Eros and Thanatos that characterize this particular dualism through the pairing of these two ancient powers. 
psychology of the people concerned - in the west the creature is bound to an "eternally malevolent nature" (Zhao 1992:49), while in the east dragons have multiple incarnations and distinct personalities. In China, for example, dragons are defined by their unique functions, with the "celestial" dragon acting as a guardian of the heavens, and the "divine" dragon being responsible for bringing rains (Zhao 1992:8, 26). But the roots of this maliciously evil western dragon appear fairly early on in the lands of Mesopotamia in particular, where the fourth tablet of the Babylonian Enuma Elish describes Marduk battling and eventually slaying the mighty Tiamat. It is here, thousands of years ago, that the notion of the dragon as monster was constructed, a construct that not only limits the expression of generally unacceptable psychic fantasies it embodies, but also seeds them within a particular creature through which they can be purged. Simultaneously, this monster typology is undoubtedly liminal, allowing safe access to unconscious fantasies by designating the dragon as a symbolic "Other". This is known as liminality, and the term which derives from the Latin limen, a doorway, is summarized practically by Van Gennep (1960:20):

... the door is the boundary between the foreign and domestic worlds, in the case of an ordinary dwelling, between the profane and sacred world in the case of a temple. Therefore to cross the threshold is to unite oneself with a new world.

Thus, by extension, a liminal creature like a dragon, is a means of passing between different psychic worlds. Turner (1990:147) describes these beings as "ambiguous" because they "are neither here nor there; they are betwixt and between the positions assigned and arrayed by law, custom, convention, and ceremonial". Furthermore, according to Plato (Soph. 254e), "the Same" and "the Other" are two of the most basic and irreducible categories. To declare something as "Other", particularly in the case of the dragon as a monster, is to declare that it is not like oneself and is thus something separate, something to be held apart. Psychologically then, this declaration is important because stating that something like a dragon is entirely "Other" allows for it to be invested with negative emotions and unsettling, inappropriate fantasies that can be either rejected or accessed in secrecy without fear of societal reprisal. For the purposes of this paper I have chosen to concentrate on two of the more renowned Greek dragons, Typhon and Python, for not only are these two great and powerful creatures known throughout ancient legend, but they are also in fact related, through both etymology and mythology. On the Zulu side I am primarily interested in pythons themselves, as in

The entire dialogue drives at the notion of their being two basic categories but "the Same" and "the Other" are specifically introduced at this point. 
Zulu belief they are perceived as extraordinarily spiritual beings and characters of myth and fairytale, in much the same way as the dragons of ancient Greece.

Typhon made his home in the Corycian cave in Cilicia, and it appears that the cave might have been guarded by the female dragon Delphyne (Apollod. 1.6.3), with whom, in some variants of the myth, Apollo did battle at Delphi. Hesiod (Theog. 824-835) provides this detailed picture of Typhon:

Strength was with his hands in all that he did and the feet of the strong god were untiring. From his shoulders grew a hundred heads of a snake, a fearful dragon, with dark, flickering tongues, and from under the brows of his eyes in his marvellous heads flashed fire, and fire burned from his heads as he glared. And there were voices in all his dreadful heads which uttered every kind of sound unspeakable; for at one time they made sounds such that the gods understood, but at another, the noise of a bull bellowing aloud in proud ungovernable fury; and at another, the sound of a lion, relentless of heart; and at another, sounds like whelps, wonderful to hear; and again, at another, he would hiss, so that the high mountains re-echoed (trans. H G Evelyn-White 1914).

Apollodorus' (1.6.3) description of Typhon is equally magnificent:

... a hybrid between man and beast. In size and strength he surpassed all the offspring of Earth. As far as the thighs he was of human shape and of such prodigious bulk that he out-topped all the mountains, and his head often brushed the stars. One of his hands reached out to the west and the other to the east, and from them projected a hundred dragons' heads. From the thighs downward he had huge coils of vipers, which when drawn out, reached to his very head and emitted a loud hissing. His body was all winged: unkempt hair streamed on the wind from his head and cheeks; and fire flashed from his eyes. Such and so great was Typhon when, hurling kindled rocks, he made for the very heaven with hissings and shouts, spouting a great jet of fire from his mouth (trans. J G Frazer 1921).

As an abomination Typhon prefigured the foul forms of his offspring, children fathered in an incestuous relationship with his own sister, Echidna. Indeed, the recapitulation of the species, so to speak, is clearly evident in the grand bestiary of creatures that are his children, for the likes of the hydra, the sphinx, chimaera, and Cerberus, gatekeeper of the underworld, were all born of his flesh (Whitlock 1983:41).

Three variants of the tale of Typhon's origins exist, ranging from the idea of Typhon as a direct descendant of the earth goddess Ge; to Hera, in her anger at the birth of Athena to her husband, begging the ancient powers of earth and sky to 
grant her a child of her own. Her prayer was granted and she bore Typhon, whom she gave to Python, the dragon of Delphi, to raise (Hym. Ap. 305-355). A third tale holds that Hera secretly obtained eggs from the old god Chronus that he had covered with his semen. Hera buried the eggs in the earth and later Typhon was born (Schol. in Il. 2.783). Regardless of which tale one follows, there is consistently a strong link with the old goddess of the earth. It is interesting then that the greatest conflict involving Typhon, a child of earth, occurs with Zeus, a sky god. Zeus must eventually resort to the power of his favourite weapon, the thunderbolt, in order to obliterate the rebellious dragon and return a state of normalcy to the universe. Fontenrose (1980:262-264) suggests that this episode is part of a generalized cycle of the "chaos dragon", and he goes on to link it to stories of the serpent Ophion, ${ }^{5}$ who was slain by Chronus in an earlier mythic cycle (Fontenrose 1980:230). He goes on to contend that because the tales of Ophion and Typhon are so similar, they are most probably one and the same creature. This fits Typhon neatly into Fontenrose's paradigm, tracing the life of the dragon of chaos from its dark origins through to a battle with a champion sky god and the eventual reconfirmation of the divine order, with either the dragon's demise or banishment. As we have seen, there is a tendency in these mythic cycles of pairing the dragon with another serpent, often a mate of the opposite sex. In the case of Typhon this mate is none other than the dragoness Delphyne, the dragon of early Delphic legend, the dragon also known as Python.

As I have noted, it was the sky god Zeus who slew the abomination Typhon. It is Apollo, the son of Zeus, who destroys Typhon's mate, Python. ${ }^{6}$ The stories surrounding Python also have several variants. While the Homeric Hymn (Hym. Ap. 302, 374) does not even mention this dragoness by name, simply making reference to a $\delta \rho \alpha ́ \kappa \alpha i v \alpha$ ("she-dragon"), Simonides (Fr. 26a) dubs the dragon of Delphi Python. He however writes of a male of the species. Apollonius Rhodius (2.706) is another to make such an observation, also referring to a dragoness. Lastly, the playwright Euripides (IT 1239-1251) tells a different story in which Apollo, but a babe in the arms of his mother, Leto, is able to slay the guardian serpent Python with a volley of arrows. By all accounts, Python was

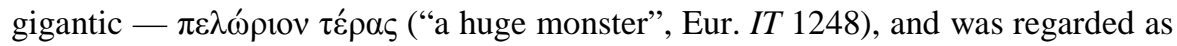
another child of the earth goddess, Ge (Eur. IT 1247; Ov. Met. 1.438-439), a

The Greek word öpı $\varsigma$ in fact also translates as "snake" or "serpent".

6 In the Classical Period, Apollo comes to be associated with the sun, in a manner similar to the association between his sister, Artemis, and the moon (Powell 1998:164). This solar connection forges another link between sky god and dragon combat as is also apparent in ancient Egyptian mythology, wherein a similar dragon combat, represented in the battle between the sun god, $\mathrm{Ra}$ (in the form of a great cat) and the demon serpent Apophis takes place. See Pinch 1994:21. 
salacious detail that provides yet another incestuous pairing - with Typhon and Echidna already mentioned, and now Typhon and Python also being born of the same mother. Here Fontenrose (1980:94) continues to expand his theory, dubbing Python (also called Delphyne) the "dragoness Delphyne-Echidna" and conflating these varied mythic cycles into one super-narrative that identifies the mate of the chaos dragon Typhon as the famous Python of Delphi. The overlap in these myths brings up yet another point of interest, highlighted yet again by the Homeric Hymn to Apollo, which in fact unifies two distinct versions of Apollo's dragon combat which Fontenrose (1980:372-373) characterizes as the mythologizing of the Apolline priesthood's violent struggle for the ancient oracular sanctuaries of Parnassus and Helicon, both of which Apollo is described as having taken by an act of force. Given the strong link between Ge, the first occupant of Delphi (Aesch. Eum. 1-8), and Python, it is conceivable that Python also had a prophetic shrine at Delphi long before the arrival of the god Apollo. Furthermore, Varro ( $L L$ 7.17) even suggests that the Delphic omphalos stone was in fact a form of Mycenaean "beehive" tomb which either marked or contained the remains of the mighty dragon. ${ }^{7}$ Therefore, in the destruction of Typhon at the hand of Zeus and in Apollo's struggle with Python we have what Cohen (1996:13) terms the "double narrative" of monsters, in that these tales serve two distinct purposes - firstly, there is the obvious mythological aspect which simply relates the monster's birth and existence, and secondly, there is another cultural application for the monster's story. Monsters are forbidding and prohibiting - think for example of the often used "Here be Monsters" written at the edges of early maps. In a social sense monsters "demarcate the bonds that hold together that system of relations we call culture" (Cohen 1996:13). Python and Typhon thus reveal the extent to which the establishment will tolerate divergent beliefs before taking action, with newly ascendant deities supplanting older powers. This sociological approach can be expanded to the level of individual human psychology with the dragon combat being a representation of the Freudian struggle between Eros and Thanatos. In this context the dragon-slayer (Zeus or Apollo) represents the forces of life and love, while the dragon itself substitutes for death and chaos, forces that need to be kept in check in the human unconscious (Fontenrose 1980:474).

The Zulu conception of dragons ${ }^{8}$ allows for the beasts to be of both the benign and malevolent varieties. There are, for example, fairytales involving

7 I would however disagree with this, preferring De Boer's 2007:81-104 more practical perspective which suggests that intoxicating gases were emitted through a bronze pipe that ran the length of the omphalos, allowing for the intoxication and "possession" of the Pythian prophetess.

8 It is worth noting that of my sources on Zulu beliefs, all are European and western in derivation. Does that mean that their western upbringing necessarily slants their view of 
many-headed serpents that are always massive and ferocious, charged with guarding rich treasure troves. In certain instances, a hydra-like beast instead defends the way to an even mightier dragon whose liver is to be used as an ingredient in the oil for anointing a new king (Canonici 1996:105-106). There is furthermore the tale of the powerful water dragon known as Inzawu, which possesses a voracious appetite that ultimately proves to be its downfall. In this tale, a man happens upon his naked mother-in-law, a person who according to Zulu custom, he is meant to hlonipha, or respect and avoid. She chooses to punish his indiscretion by setting him a Herculean task, namely that he return with a piece of the liver of the mighty dragon Inzawu, in a scene perhaps reminiscent of the Callimachean description of Tiresias' unfortunate witness to the bathing of the goddess Athene (Callim. Hymn 5). The young man decides to set a trap for Inzawu by digging a great pit and filling it with sharp assegais. He completes his deception by enticing the dragon to pursue him by feeding it pancakes, a special weakness of Zulu dragons! This does however bear a striking similarity to the tale of the dragon that dwelt upon the Athenian acropolis and supposedly survived by eating honey cakes that were left as monthly offerings (Hdt. 8.41). In the end, and following a lengthy chase and many pancakes, the now cumbersome bulk of the extremely well-fed Inzawu causes it to stumble fatally into the concealed pit trap (Du Toit 1976:38-42).

In the Zulu tradition, the cult of the ancestors and an accompanying deep and abiding respect for one's forebears are of paramount importance in both a religious and a social sense. The spirits of the departed ancestors are typically referred to as "shades", the amadlozi or amatongo, and the great python snake is called inkhosi yamadlozi or the "lord of the shades" (Berglund 1976:142). ${ }^{9}$ Furthermore, the python is also associated with the "Lord-of-the-Sky"

Zulu belief, or that they see dragons where there are none? I would argue that this is not the case, for while the Christian religious bent of many of the earliest scholars of Zulu culture (e.g. Callaway) would tend to give their comments the perspective of the earliest anthropologists looking down on the "superstitions" of the local "native" population, others like Berglund made a great effort to learn isiZulu for themselves and so, being able to communicate with people without the filter of an interpreter, were better able to assemble works that carefully catalogue the traditions and beliefs of the Zulu people with far less bias than their predecessors.

9 Allen \& Griffiths 1979:12 note that the python was also central to the snake cult in Dahomey: "The great immortal python was kept in a temple or snake house, with many other snakes, but he himself was only visible to the priests, although the king was allowed to see him once in his lifetime. The python was almighty, omniscient and oracular and was prayed and sacrificed to and given gifts. He had a thousand snake wives, or priestesses, who had either been given to the god at birth and brought up in the temple or had been 'chosen' by him later. Any girl or woman overcome by hysteria was said to have been chosen, or touched, by the great python". 
(inkhosi yezulu), the Zulu creator deity, in essence likening it to Python and Typhon who are also linked with sky gods in their own way. This association is a positive one for the Zulu, as the creator is an extremely benevolent power, whilst for the ancient Greeks the association tends to be one of violence with the sky god having to establish his domination over the draconic creature. The Zulu python is often also a symbol of fertility in the same manner as the Chinese dragon (Hambly 1929:660). However, the most significant aspect of the place of the python in Zulu belief is its relevance to the practice of divination, something that differentiates it from the dragons of Greek belief, given that although Python has an important place in the mythology of the Delphic sanctuary, it does not hold a direct and immediate connection with the practice of divination as seen in Zulu lore. This despite the possibility of there once being an oracular shrine dedicated to Python at the Delphi. The python has a particularly important place in the dreams that are said to call Zulu youths to their vocation as diviners. ${ }^{10}$ The basic pattern of these dreams suggests that the python functions as a guide - the python reveals a great pile of powerful herbal medicines to the dreamer who is surrounded by numerous shade-snakes, spirits of the dreamer's ancestors who have taken the form of serpents. ${ }^{11}$ It is a commonplace that the spirits of the ancestors are capable of assuming the forms of a variety of snakes, based on their stature in society (Callaway 1870:196). ${ }^{12}$ This guiding python often bears a lamp upon its head, a noteworthy dream symbol in itself. The python then speaks to the assembled shade-snakes and inquires of them if the dreamer is the one who has been called to become an isangoma. The shade-snakes must concur before the python permits the dreamer to symbolically take from the pile of medicines that it guards (Berglund 1976:141), in essence gaining access to the python's supernatural wisdom.

Kohler (1941:19-21) provides a somewhat more menacing variant on this "calling", in which a young trainee is practically hounded into the presence of the python by a "huge black monster with fiery nostrils" that leaves the trainee absolutely terrified. The appearance of two powerful serpents brings to mind the similar pairing of dragons in Greek mythology, with one dragon leading the trainee diviner into the presence of another. Ultimately, in the Zulu tradition the python is a benevolent being, imparting mystical knowledge to those who seek its spiritual guidance. To illustrate this position, one of Berglund's (1976:181) informants adamantly insists that "the python is not an animal" because it is in fact one of the

10 The Zulu word for a diviner is isangoma, differentiated from the inyanga or herbalist.

11 Nilsson 1950:328 notes that ancient Greek folklore had similar notions of ancestors taking the form of serpents.

12 Although Callaway is an extremely dated and biased source, he does note that the shade of a chief can become either the black or green mamba, while several other kinds of snake are reserved for the wives of the chief and the common people below them. 
amakhosi, the great chiefs. A more benevolent streak is reflected in Zulu oral traditions as well, wherein the python can often represent a healer after the manner of Asclepius, and yet in keeping with the duality that marks all legendary serpents, it is the lizard in the classic fairytale that is originally responsible for bringing death into the world of men through his act of carelessness (Canonici 1996:83, 91).

Let us then conclude by analyzing the differing cultural approaches to the image of the dragon. Newman (1979:207) points out an obvious sexual and phallic symbolism to the draconic worm shape, something perhaps even evident in the relationship between the python and the female isangoma. In ancient Greece this sexuality is revealed in the tales of Aelian (NA 11.2), who writes of the sacred serpents kept at Epiros, descendants of Delphi's own Python, which were to be fed only by a virgin priestess. The penetrative aspect to this sexual symbolism is even to be found in the story of St. George the Dragon-slayer, who sexually penetrates the dragon with his lance in an act which theorists describe as the ultimate display of the triumph of patriarchal Christianity over the sacred feminine of paganism (Newman 1979:17). However, Zhao (1992:137) argues that for the German poet Schiller, battling the dragon was instead to struggle against one's own emotions in order to conquer fears and desires. In this far more Jungian sense, the dragon is the archetype par excellence, with the individual ego represented by the dragon-slayer, and their struggle for supremacy depicting the battle between the ego and the darker aspects of the psyche in entirely mythic terms (Henderson 1990:120). As to the mythic language of a sky god conquering the evil dragon, it is quite literally the triumph of light over darkness in the individual psyche, for only through grappling with these darker parts of the mind can a person truly come to terms with all that he or she is (Henderson 1990:120-121). White (2004) illustrates this psychological process through her investigation of the epic Beowulf, wherein she holds that the eventual defeat of Grendel mythically describes the path of human advancement toward the wholeness of the psyche. And yet, this perspective only applies if the dragon is as malevolent as the western world believes. Jung (1968:89) himself summarizes this draconic struggle from another perspective:

The dragon, or serpent, represents the initial stage of unconsciousness, for this animal loves, as the alchemists say, "to dwell in caverns and dark places". Unconsciousness has to be sacrificed; only then can one find the entrance into the head, and the way to conscious knowledge and understanding. Once again the universal struggle of the hero with the dragon is enacted, and each time at its victorious conclusion the sun rises, consciousness dawns ... 
From this different point of view then, the dragon is no longer associated with a struggle for identity and mastery over the elements of the self, but with a struggle for the acquisition of knowledge, be it knowledge of self or "Other". This is the place held by the python in Zulu society, for while it can indeed be a horrible monster with its constricting and confining prowess, it is also a mystical healer and benefactor, a teacher and spiritual guide, bringing relief to the often psychically agitated young person who must recognize the truth of their calling to the status of diviner before they will become psychologically whole, a process that certainly mirrors the Jungian approach that I have discussed. It is a curious happenstance that in some Zulu tales the python will actually constrict around a person in order to confer its blessings, the perfect expression of the potential for creation and destruction that marks the legend of every dragon. Furthermore, in the context of Jung's (1968:89) idea discussed above, the python brings with it Outsider knowledge or knowledge of "the Other". Cohen (1996:20) states that:

Monsters are our children. They can be pushed to the farthest margins of geography and discourse, hidden away at the edges of the world and in the forbidden recesses of our mind, but they always return. And when they come back, they bring not just a fuller knowledge of our place in history and in the history of knowing our place, but they bear self-knowledge, human knowledge - and a discourse all the more sacred as it arises from the Outside.

While it is ultimately knowledge of the ages and of the ancestors, it is still a human knowledge that draconic figures in turn mythologize and shape into the iconic experiences of human existence, and indeed, few events can be more iconic in Zulu culture than the call to become an isangoma.

\section{BIBLIOGRAPHY}

Allen, J \& Griffiths, J 1979. The book of the dragon. London: Orbis.

Berglund, A-I 1976. Zulu thought-patterns and symbolism. Uppsala: Swedish Institute of Missionary Research.

Canonici, N N 1996. Zulu oral traditions. Durban: University of Natal.

Cohen, J J 1996. Monster culture (seven theses). Minneapolis: University of Minnesota Press.

De Boer, J Z 2007. Delphi's small "omphalos": An enigma. Syllecta Classica 18:81-104.

Dodds, E R 1951. The Greeks and the irrational. Berkeley: University of California Press. 
Du Toit, B M 1976. Content and context of Zulu folk-narratives. Gainesville: University Presses of Florida.

Fontenrose, J 1980. Python, a study of Delphic myth and its origins. Berkeley: University of California Press.

Freud, S 1947. (trans. J Riviere) The ego and the id. London: Hogarth Press.

Gilmore, D D 2003. Monsters: Evil beings, mythical beasts, and all manner of imaginary terrors. Philadelphia: University of Pennsylvania Press.

Henderson, J L 1990. Ancient myths and modern man. In Jung, C G, Von Franz, M-L, Henderson, J L, Jacobi, J, Jaffe, A, Man and his symbols, 104-157. London: Arkana.

Huxley, F 1979. The dragon. Nature of spirit. Spirit of nature. London: Thames \& Hudson.

Jung, C G 1968. (trans. R F C Hull). Alchemical studies. London \& Henley: Routledge \& Kegan Paul.

Lambert, M 1990. Nomkhubulwana: The Zulu Demeter. Akroterion 35:46-59.

Lambert, M 1993. Ancient Greek and Zulu sacrificial ritual: A comparative analysis. Numen 40:293-318.

Lambert, M 1995. Ancient Greek and traditional Zulu medicine: A question of balance. Acta Classica 38:71-88.

Newman, P 1979. The hill of the dragon: An enquiry into the nature of dragon legends. Bath: Kingsmead Press.

Nilsson, M P 1950. The Minoan-Mycenaean religion and its survival in Greek religion. Lund: C W K Gleerup.

Pinch, G 1994. Magic in ancient Egypt. London: British Museum Press.

Powell, B B 1998. Classical myth. Upper Saddle River, NJ: Prentice Hall.

Ragin, C C 1994. Constructing social research: The unity and diversity of method. Thousand Oaks, California: Pine Forge Press.

Turner, V 1990. Liminality and community. In Alexander, J C \& Seidman, S (eds.), Culture and society. Contemporary debates, 147-154. Cambridge: Cambridge University Press.

Van Gennep, A 1960. (trans. M B Vizedom \& G L Caffee) The rites of passage. London: Routledge \& Kegan Paul.

White, J A 2004. Hero-ego in search of self: A Jungian reading of Beowulf. New York: P Lang.

Whitlock, R 1983. Here be dragons. London: Allen \& Unwin.

Zhao, Q 1992. A study of dragons, East and West. New York: P Lang. 